\title{
Beyond Methodological Eurocentricism: Comparing the Chinese and European Legal Traditions
}

\author{
Taisu Zhang*
}

\section{INTRODUCTION}

The comparative study of Chinese and European legal history is arguably as old as the social sciences themselves. Comparisons between the "Chinese legal tradition" and European ones lie, after all, at the heart of Max Weber's seminal studies on economy and society-hardly surprising, given Weber's extensive legal background. ${ }^{1}$ In recent decades, comparative Chinese and European legal history, broadly defined, has thrived in both Chinese academic circles and foreign ones, across a number of disciplines, including history, law, economics, and sociology. This article reviews the basic trends in this literature and suggests avenues for future research, both thematic and methodological. Given its length limitations, it makes no claim to be a comprehensive survey of the "field," if we can call it that. Rather, it seeks to highlight some of the major intellectual themes that, in the author's perhaps idiosyncratic experience, scholars in the field have regularly grappled with, with varying levels of success. The goal, ultimately, is to discuss how progress might be made.

Existing studies seem to fall, for the most part, into three general categories: the first, most densely populated category includes works that use comparative methods as an illustrative tool. Historical Chinese institutions are compared with functionally similar European ones, so that we can better understand their structure, operation, and, in some cases, origins - rarely are these works focused on better understanding European institutions. The second category, increasingly prominent in recent years, studies historical interactions between China and the West, including the translation of legal texts and treatises, imperial and colonial experiences, and disputes in the international legal arena. The third category includes what one might call "divergence studies," which seek to explain how and, more importantly, why Chinese and

* Associate Professor, Duke University School of Law; Irving S. Ribicoff Visiting Associate Professor, Yale Law School.

1 See Max Weber, Economy and Society 1063 (Guenther Roth \& Claus Wittich eds., 1968); Max Weber on LAW IN ECONOMY and Societr 232-44 (Max Rheinstein ed., 1954). For criticism, see Robert M. Marsh, Weber's Misunderstanding of Chinese Law, 106 AM. J. Socrol. 281 (2000).

(c) The Author 2016. Published by Oxford University Press. All rights reserved.

For Permissions, please email: journals.permissions@oup.com 
European institutions differed, generally in the context of early modern global economic divergence.

The first category, which has been particularly popular in Mainland China, has expanded Sino-European comparisons into an ever-wider array of legal issues, moving well beyond the traditional focus on penal law. ${ }^{2}$ It has also made Chinese legal history more easily accessible to a wide range of social sciences, which would otherwise have some difficulty digesting the material. At the same time, however, such "translation"- despite the intellectual enrichment it provides-comes at significant analytical cost: by focusing on the Chinese end of the comparison, and using European narratives primarily as reference points, it arguably perpetuates preexisting imbalances in our understanding of global legal history, in which studies of "Western" history continue to analytically color the study of other legal traditions, rendering us unable to engage them on their own terms, or even through their own legal language. This "methodological Eurocentricism" continues to be surprisingly resilient in comparative history, despite decades of academic criticism. Chinese scholars themselves have been at least as guilty of this as those who work from abroad, creating a curious "reverse orientalism" that permeates large sectors of Chinese legal academia.

The second category is, in many ways, a reaction against this longstanding imbalance: it seeks to place China and "the West" on more equal analytical footing by examining the ways in which Western legal systems evolved in reaction against the Chinese "other." This echoes a growing tendency among scholars of both colonial history and international law to emphasize the legal impact of the colonial "periphery" on the European "center." Successful as it most certainly has been, this vein of scholarship has its own share of problems: precisely because it focuses on actual legal encounters between China and the West, it seems to dance around, rather than confront head-on, the difficulties implicit in the kind of functionalist comparison attempted in the first category. The Sino-European comparisons that these "legal encounters" studies focus on are, for the most part, those conducted by early modern historical actors within the specific context of their colonial experiences, rather than those conducted by the authors themselves from a (potentially) more objective, functionalist perspective. The two categories ask, therefore, fundamentally different questions: crudely summarized, the first category seeks primarily to explain why Chinese and European institutions differed, whereas the second category focuses more on explaining how those (perceived) differences actually mattered.

The third category_- "divergence studies"- seeks to tackle both questions. It returns to the functionalist method, but does so within a more concrete historical context that explains why the differences between the Chinese and European legal traditions were historically significant. It examines, depending on one's preferred terminology, either "the rise of the West" or "the relative decline of China" from an institutional dimension: what were the institutional differences that are commonly

2 For an example of the traditional penal law oriented literature, see DERK BODDE \& CLARENCE MoRRIS, LAW IN IMPERlal China (1967). The current "countermovement" against the penal law-focus began, for the most part, with CIVL LAw In QING and Republican ChINa (Kathryn Bernhardt \& Philip C.C. Huang eds., 1994). 
thought to have contributed to the material divergence between China and Europe in the modern era? Did they in fact contribute, and in what sense? What explains these institutional differences? The primary difference between this category and the first category is that "divergence studies" make a somewhat clearer argument for why comparisons between Chinese and European legal history are academically significant: legal comparisons can help us understand the economic and geopolitical power shifts that, for better or worse, defined much of modern world history.

Given the questions that it seeks to answer, "divergence studies" necessarily extends far beyond the confines of the history profession. In its current state, it already draws from virtually all the social sciences, and has taken advantage of this methodological diversity to make enormous advances in our understandings of Chinese and European legal and economic history. There are, however, shortcomings in the preexisting literature: most importantly, it is largely separated into those studies that examine the socioeconomic consequences of legal institutions and those that examine their origins. Rarely are the two merged into a unified thesis, even when such unification would add significant depth and power. In many ways, this disconnect lays bare the methodological tensions created by the intersection of multiple academic disciplines within "divergence studies."

The remainder of this article is organized as follows: sections A, B, and C discuss, respectively, categories one, two and three. A short conclusion explores-very tentatively-whether an expansion of category three to cover a greater variety of geographical regions can plausibly generate a "category four" that analyzes early modern and modern legal development in a somewhat more general and theoretical manner, and therefore can speak more directly to normatively-minded scholars.

\section{A. "Illustrative comparisons"}

I have labelled studies belonging to category one "illustrative comparisons" because their basic objective is, at least self-avowedly, simply to highlight particular features of Chinese or European legal history through a comparative exercise. It is probably fair to say that this is the most straightforward of the three categories. For the most part, works in this category ask how historical Chinese and (some) European law handled a particular legal issue - in other words, they select functionally similar legal institutions from both sides-and identify the primary differences and similarities. In many cases, the analysis ends at this stage. ${ }^{3}$ In others, the author(s) will attempt to explain the differences, some speculatively, others in fairly exhaustive detail. ${ }^{4}$

3 For example, the sections of Zhang Jinfan. Zhongguo Falu de Chuantong yu Jindai Zhuanxing [The Tradtions and Early Modern Transformation of Chinese LaW] (1997) that apply a comparative method do so in a purely descriptive fashion. Another fairly well-known example is Fan Zhongxin, Zhongxi Falü Chuantong zhong de "Qin Qin xiang Yin" [The Practice of Kinsmen Concealing Each Other's Misconduct in the Chinese and Western Legal Traditions], 1997(3) Zhongguo SHeHul Kexue [CHInese SOClal SCIENCES] 87.

4 Some have attempted to expand Zhang Jinfan's descriptive comparison into a causal thesis: see, e.g., Zhang Benshun, Ziran Dili Huanjin Shiye xia de Zhong Xi Falü Chuantong [Chinese and Western Legal Traditions from an Ecological Perspective], 2013(6) Xibu Faxue Pinglun [Western China Legal Science Review] 78; Fan Zhongxin, Ziran Renwen Dili yu Zhonghua Falü Chuantong zhi Tezheng [Cultural Geography and the Characteristics of the Chinese Legal Tradition], 25(3) XIAndai FaXue [MOdern LeGal SCIence] 40 (2003). 
The value of such methods lies, first and foremost, in the general truism that comparison draws our attention to things we otherwise would not have noticed. For example, a common theme in this literature is that English, and perhaps Western European, legal history evolved upon the basis of both the separation of church and state and the division of the state into feudal jurisdictions, both of which not only limited the authority of the nominal sovereign, but also encouraged institutional competition between these often overlapping jurisdictions. ${ }^{5}$ In comparison, Chinese law is often thought of as being centralized under the absolute authority of the emperor. A common argument based on this comparison is that the centralization of legal authority in China discouraged the "rule of law," while the segregated nature of European law encouraged political compliance with legal rules. ${ }^{6}$ Whereas the intuitions behind these arguments may seem completely obvious to many scholars, they would be much less so without the comparison: as a purely theoretical matter, at least, there are other possibilities. For example, centralized political entities could nonetheless be motivated to establish the "rule of law" to bind their successors, and indeed their greater coercive capacities might have allowed them to do so more effectively than a segregated legal system.

In addition, such comparisons also enhance the accessibility of Chinese legal history to scholars in the other social sciences, most of whom-even those who received their education in Mainland China-have been trained in a Western style system. To them, understanding historical Chinese institutions via their similarities and differences with Western ones is likely easier than simply engaging with Chinese history through its own concepts and language: for example, the concept of "mortgage" or "collateralized debt" most familiar to Chinese economists is, in all likelihood, the "modern" concept employed in contemporary Chinese law, which was transplanted from German and Japanese sources in the early $20^{\text {th }}$ century. ${ }^{7}$ Historical Chinese collateral transactions are perhaps most easily understood, therefore, as "mortgages" with adjusted features, rather than as "conditional sales" - which is how a landowner in $19^{\text {th }}$ century North China, for example, likely would have understood them.

There is a fairly straightforward historical explanation for this state of affairs: by and large, the Chinese social sciences, including history and law, had to be rebuilt after the Cultural Revolution. ${ }^{8}$ By this time, the society that these newly trained social scientists lived in had already adopted large amounts of nominally "Western"including Soviet-institutions, and the predominant analytical methods taught in universities were adapted (or simply copied wholescale) from Western sources. ${ }^{9}$ The

5 For example, Xu Aiguo, Xifang Guojia Fazhi de Xingcheng dui Zhongguo de Canzhao [The Development of the Rule of Law in Western Countries and its Reference Value for China], 403 RENMIN LUNTAN [PeOPLE'S Forum] 5 (2013), available at http://paper.people.com.cn/rmlt $/ \mathrm{html} / 2013-05 / 11 /$ content_1250273.htm?div=-1.

6 Id.

7 For example, LIang Zhiping, Qingdal Xiguan Fa: Shehui Yu Guojla [Qing Customaky Law: Society and State] 93 (1996); Wu, Xianghong. Dlan zhi fengsu yu Dlan zhi falú [The Customs and laws Regulating "Dian” Sales] (2009).

8 See Yu Sanding, Xueshu de Zijue yu Xuezhe de Zili: Dangdai Xuezhe Yanjiu [The Self-Awareness of Scholarship and the Independence of Scholars: A Study on Contemporary Scholars] (1998).

9 See, eg Xu Youyu, Zhongguo Dangdai Zhengzhi Wenhua yu Xifang Zhengzhi Zhexue [Contemporary Chinese Political Culture and Western Political Philosophy] (2008). 
severe social and political turmoil of the $20^{\text {th }}$ century, coupled with extremely rapid industrial growth after the mid-century, created an enormous experiential gap between end-of-century academics and the historical world that existed before 1911, or even 1949. In many ways, comparative studies help them bridge the gap as much as they would help, for example, an American legal scholar attempting to understand Qing property institutions, or Republican corporate charters.

This comes, however, at a significant risk: there is always the danger that something is "lost in translation"-some subtle but perhaps significant aspect of Chinese law actually becomes harder to understand once we explain them via comparison to European ones. Do comparative methods encourage us to overemphasize the differences, or overlook deeper distinctions that course beneath facial similarities? The common condemnation of much comparative history as "Eurocentric" is, most obviously, a condemnation of the normative assumption that "other parts of the world must become like Europe to 'develop' or 'modernize," ${ }^{10}$ but it can also be a condemnation of empirical biases, of the need to understand or explain non-European concepts as mutations of European ones. The latter may, in fact, be much more difficult to overcome than the former.

Paradoxically, one consequence of the latter - a more "methodological" kind of Eurocentricism, rather than normative or thematic-is that the great majority of these "illustrative comparisons" focus primarily on China. ${ }^{11}$ The bulk of their primary research lies in Chinese archives, whereas the European comparison is derived from preexisting secondary material, very little of it comparative in nature. At the individual level, this is often perfectly reasonable, as many scholars may simply be more fluent in the Chinese side of the comparison, or care more about it. When, however, it becomes a common trait across virtually an entire subfield of comparative studies, it suggests the existence of certain systemic biases: even today, many, arguably most, scholars seem to accept that we can learn more about Chinese legal history by comparing it with Europe, but rarely does the assumption extend in the opposite direction-that we can learn more about Europe by comparing it with China. The critical analysis that the comparison enables only applies to the Chinese "subject," and not to the relatively unquestioned European "paradigm." The danger here is two-fold: first, European legal history does not benefit enough from the cross-examination and analytical enrichment that rigorous comparison potentially provides - in fact, we are arguably not learning anything about European law via the comparative exercise that we could not learn just as easily should we discard the Chinese comparison altogether. Second, by pegging Chinese legal history into what are essentially European analytical holes, we risk seriously misunderstanding it.

That these tendencies are also prevalent-arguably more so-among Mainland Chinese scholars is hardly surprising. As noted above, the social sciences, history included, were more or less "rebooted" after 1976 on the mainland, under

10 Immanuel Wallerstein, Eurocentricism and Its Avatars: The Dilemmas of Social Science, 46 SocioLoGICAL BuLletin 21 (1997); Arif Dirlik, Is There History After Eurocentrism?: Globalism, Postcolonialism, and the Disavowal of History, 42 Cultural CritiQue 1 (1994).

11 This is broadly true of all material cites in supra notes $3-5 . \mathrm{Xu}$, supra note 5 , devotes more space to Western legal history, but relies completely on secondary material when doing so, and comes back in the end to "how Western legal traditions can inform our understanding of China." 
predominantly "Western" intellectual influence. This occurred at roughly the same time that the Chinese intellectual world began to reject Communist ideology in favor of "Western liberalism," however defined. Combined, these trends dramatically boosted the stature and prestige of Western, particularly American, scholarship in China, and led several generations of scholars, beginning in the 1980s, to "self-orientalize," for lack of a better term. More recently, this has triggered a fierce backlash from those who advocate the development of a uniquely Chinese paradigm of legal development, free from what they see as Western intellectual dominance. ${ }^{12}$

Within the confines of comparative legal history, these tendencies are perhaps most clearly observed in the most public law-oriented-and therefore most visiblefields. The aforementioned essay on the separation of powers, for example, draws the conclusion that, in some basic sense, China simply did not have a real "legal tradition" to speak of-and, judging by the exacting standards through which the paper defines "the rule of law," likely still does not have one. ${ }^{13}$ This basic message, that the Chinese legal tradition lacks some desirable feature that the "Western legal tradition" possesses, is, in the author's experience, a fairly common one among "illustrative comparative histories."

Even the studies that expressly reject this message often cannot help but analyze Chinese institutions via distinctively "Western" analytical frameworks, many drawn directly from the author's exposure to European and American legal history. For example, a recent study on Chinese constitutional history argues against the common presumption that, because Chinese law did not expressly limit the highest political actor's authority, it therefore had no tradition of constitutionalism. The author argues that this understanding of "constitutionalism" is too narrow, and that a more expansive, "functionalist" definition will pave the path towards a fairer analysis of Chinese constitutional history. ${ }^{14}$ If we understand "constitution" in what the author considers to be the "original meaning" of the word - the act of "constituting" the state through legal and political documents and defining its fundamental functions-then not only does China have a rich "constitutional" history, but also an arguably successful one. But how does the author derive this "original meaning"? Ironically, by looking at Western European constitutional history, and redefining the term within his interpretation of this European, and particularly English, historical context. In the end, the book leaps from one "Eurocentric" constitutional paradigm to another.

There are, of course, exceptions to the general trend. A recent study by Zhiqiang Wang, for example, compares the use of precedent in early modern Chinese, English, and French adjudication, reexamining the political and intellectual foundations that underlay each system through detailed comparison with the other two. ${ }^{15}$ Core concepts, including the very notion of "precedent," are considered and remodeled over the course of the comparative exercise, leading to a tighter definition that facilitates

12 For an early and influential example, see Deng Zhenglal, Zhongguo Faxue XIANG Hechu Qu [Where Should Chinese Legal Studies Go?] (2006).

$13 \mathrm{Xu}$, supra note 5. See also, He Weifang et al., Fazhi ji Qi Xifang Ziyuan [The Rule of Law and Its Western Resources], 2011(1) Zhongshan Daxue Falü Pinglun [Sun Yat-Sen University Law Review] 45.

14 Zhu Sul, The Constitution of Ancient China (forthcoming, Princeton University Press).

15 Zhiqlang Wang, Case Precenent in Chinese and Western Legal Traditions (book manuscript in progress, on file with author). 
more refined functional comparisons. Clearly, this is one productive way forward from the current state of affairs.

Analytical imbalance is, in any case, only one of several basic problems with "illustrative comparisons." An arguably more fundamental one is how to justify the choice to compare China with Europe: given all the comparative pairings available, why choose this particular one? Why focus so much on East-West comparisons, rather than East-East, or perhaps East-South, comparisons? Is this merely another manifestation of our subconscious "methodological Eurocentricism"- that the history of "developing countries" must be compared to that of the developed world to gain relevance and salience, or perhaps that non-European societies must continue to obsess over how they legally "failed" (but in what sense, other than not having the same features as Western systems)? Much recent scholarship on Sino-European comparisons expressly struggle with these questions, and respond in a variety of ways. Two of the most common strategies are examined in sections $\mathrm{B}$ and $\mathrm{C}$.

\section{B. Sino-European "legal encounters"}

A number of scholars have responded by studying the actual historical encounter between Chinese and European legal ideas and institutions in the early modern era, as well as the consequences of these encounters. In other words, Sino-European comparisons mattered because they influenced the actual trajectory of legal change in both China and Europe. Many-although certainly not all—of these studies explicitly attempt to push back against the "Eurocentric" or "orientalist" tendencies discussed above by emphasizing the "feedback effect," so to speak, that Chinese law had on European legal discourse. In doing so, they echo a growing tendency among scholars of both imperialism and international law to acknowledge the intellectual and legal impact that the colonial "periphery" had on the European imperial "center." Whereas earlier generations of scholars focused primarily on the influence that, for example, British imperialism had on sociopolitical identity and institutions on its various Asian and African colonies, much recent work argues that influence also flows in the opposite direction. ${ }^{16}$

Two of the most compelling examples are Li Chen's Chinese Law in Imperial Eyes, and Teemu Ruskola's Legal Orientalism. Chen's manuscript examines "the formation and transformation of Western knowledge" in response to its perception of Chinese law and society in the century leading up to the Opium War. ${ }^{17}$ It begins by narrating a number of early encounters between European merchants and the pre-1840 Qing state-which was, as Chen observes, suspicious of foreigners and institutionally unaccommodating - and then explains how these encounters informed and, to some extent, shaped European debates about the ideals of modern law and government in the $18^{\text {th }}$ and early $19^{\text {th }}$ centuries, laying much of the legal foundation for the later $19^{\text {th }}$ century imperial experience.

16 For example, Lauren Benton, a Search for Sovereignty: LaW and Geography in European Empires, 1400-1900 (2009); Antony Anghie, Imperlalism, Sovereignty, and the Making of International LaW (2005); Lauren Benton, LaW and Colonial Cultures: Legal Regimes in World History (2001); Antony Anghie, The Evolution of International Law: Colonial and Postcolonial Realities, 27 THIRD WORLD Q. 739 (2006); James T. Gathii, Imperialism, Colonialism, and International Law, 54 BuFF. L. REV. 1013 (2007).

17 Li Chen, Chinese Law in Imperdal Eyes: Sovereignty, Justice, and Transcultural Politics (2015). 
Chronologically, Legal Orientalism picks up largely where Chinese Law in Imperial Eyes leaves off-in the later $19^{\text {th }}$ century, when Western imperial powers had already established their military, economic, and diplomatic dominance over a weakened Qing state. ${ }^{18}$ With this material dominance came new forms of legal imperialism, including the establishment of extraterritorial jurisdictions in major Chinese ports. Ruskola's core argument is that, partially fueled by these experiences, the notion of a "lawless" and stagnant Chinese "other" soon became a critical component of Western, and particularly American, legal and political identity, in that it reinforced (and still reinforces) the notion that law and "the rule of law" are somehow unique, and therefore central, to Western political systems. To sustain this perception, consciously or not, generations of Western lawyers and scholars insisted on misinterpreting basic facts and experiences about Chinese law, ranging from court systems and evidentiary procedures to corporate institutions, in a way that was consistent with the notion of Chinese "lawlessness."

These studies, and others like them, ${ }^{19}$ add a much-needed dimension to our understanding of Sino-European legal interactions. Turning "Eurocentricism" on its head, they allow the European side of the comparison to become more than a staid analytical reference point, more than an unresponsive "source" or "center" that exists merely to highlight the evolution of Chinese law. It is somewhat ironic that Ruskola's research on Western legal development in light of its imperial experience reveals a persistent campaign by American and European lawyers to portray the Chinese "other" as itself staid and unresponsive to the forces of modernity. Even so, uncovering this act of distortion breathes life and intellectual dynamism-perhaps of dubious quality, but dynamism nonetheless - into the history of Western legal imperialism.

Despite its many achievements, there are limitations to the "legal encounters" methodology: first, given its subject matter, it necessarily focuses on institutions that played an actual role in the historical interaction between China and Europe. This privileges certain parts of the legal apparatus-those related to international commerce and diplomacy, for example-over others-those related to domestic civil matters, for example - and may leave entire portions of the apparatus out in the cold.

In addition, the kind of comparison that these studies engage in is, for the most part, second-hand. Again because of their subject matter, they necessarily focus more on how historical actors understood the Sino-European comparison than how the authors themselves understood that comparison. While there is much to be said about this approach, it also precludes the kind of functionalist (and hopefully more objective) comparison that many, perhaps most, comparativists still consider to be the fundamental mission of comparative law-and that "category one" comparisons largely belong to. ${ }^{20}$ The specific manner in which the "legal encounters" approach dances around the methodological problems discussed above can be somewhat

18 Teemu Ruskola, Legal Orientalism: China, the United States, and Modern Law (2013).

19 In some ways, the predecessors to these studies is Jonathan Spence, The Khav's Great Continent, China IN Western Minds (1998), and the literature on Western conceptions of China that it came to (somewhat) represent.

20 Konrad Zweigert \& Hein Kötz, An Introduction to Comparative Law (Tony Weir trans., 3d ed., 1998); Ralf Michaels, The Functional Method of Comparative Law, in THe OxFord Handbook of Comparative Law 339 (2006). 
unsatisfying in this regard. It cannot really solve those problems because it has, in a very fundamental way, changed the nature of the inquiry: instead of asking "how and why did Chinese and European laws differ," as category one tends to do, it asks "how did those differences matter." The answer it provides-that contemporary perceptions of difference impacted legal development on both sides-actually renders the former question somewhat meaningless: what mattered were perceived differences, instead of real ones.

\section{C. "Divergence studies"}

Is there a way to do comparative Sino-European legal history that addresses both questions in a more synthetic manner? One solution that has begun to gain traction in recent years, due to the ascension of New Institutional Economics, is to do the comparison within a broader context of global economic divergence - that is, to ask how Sino-European institutional differences affected their respective economic performance, and then to explain how those institutional differences emerged in the first place. ${ }^{21}$ This gives an immediate and powerful answer to the question of "why does the comparison matter": it matters because it helps us understand one of the most consequential power shifts-from China to Western Europe-in human history. The challenge is then to demonstrate that legal differences actually helped generate the "Great Divergence,"22 or at least some portion of it. Much more so than the previous two categories, "divergence studies" are innately linked to a clear and fairly definite objective: to illustrate and then explain the $19^{\text {th }}$ century economic divergence between China and Western Europe. Its progress is, therefore, measured by how successfully it does this, rather than by other, more artificial standards. The field is therefore "functionalist all the way down," in its choice of which institutions to compare, the ways in which it compares them, and, ultimately, which comparisons are deemed more successful than others.

The centerpiece of the divergence was, of course, the basic fact that Western Europe began large-scale industrialization nearly two centuries before China. At present, scholars have yet to produce anything close to a generally accepted "theory of industrialization," which means that it is very much an open question whether-and which-legal institutions had anything to do with the divergence. One benefit of this state of affairs is that it preempts the kind of analytical imbalance that tends to characterize "category one" studies: the danger of forcing Chinese facts within European theoretical paradigms is lessened because there really is no "European paradigm" to speak of. Many of the most influential works in the field focus, in fact, more on the European side, seeking to understand the socioeconomic performance of English,

21 For example, Christopher Isett, State, Peasant and Merchant in Qing Manchurda: 1644-1862 (2007); David Faure, China and Capitalism: A History of Business Enterprise in Modern China (2006); Debin Ma, Economic Growth in the Lower Yangzi Region of China in 1911-1937: A Quantitative and Historical Analysis, 68 The Journal of ECONomic History 355-392 (2008); Robert Brenner \& Christopher Isett, England's Divergence from China's Yangtze Delta: Property Relations, Microeconomics, and Patterns of Development, 61 J. OF AsLAN STUD. 609 (2002); Kenneth Pomeranz, Land Markets in Late Imperial and Republican China, 23 Continuity \& Change 101 (2008).

22 The most famous use of the phrase is, of course, Kenneth Pomeranz, The Great Divergence: China, Europe, AND the Making of the Modern Wordd Economy (2000). 
Dutch, or French law via comparison to functionally similar Chinese institutions. ${ }^{23}$ Those that focus more on the Chinese side, nonetheless, attempt to approach European history with a critical and reexamining eye. ${ }^{24}$

This is not to say that there have been no attempts to create a "European paradigm"-only that they have been, for the most part, unsuccessful. Douglass North's argument that secure property rights drove "the rise of the Western world" is probably as close to a "paradigmatic argument" that the field has generated since the mid- $20^{\text {th }}$ century; however, even that has generated much more skepticism than accord over the past two decades. ${ }^{25}$ More recent scholarship has fairly persuasively demonstrated that many Asian societies, particularly China, actually provided strong institutional protection for private property rights-even if the state was not necessarily the entity that provided such protection. ${ }^{26}$ The economically significant differences between Chinese and Western European law, if they indeed existed, lay elsewhere.

The sheer magnitude of the causal problem faced by "divergence studies" may have helped prevent premature coalescing around potentially misleading paradigms. One could argue that descriptive paradigms - such as "China lacked the rule of law" - are perhaps easier to perpetuate than causal ones - such as "China's lack of the rule of law hampered its economic development"-if only because the latter involve more moving parts, and are therefore more difficult to support, even superficially. When the causal problem is as large and difficult as explaining global economic divergence, it is wholly unsurprising that no dominant explanation has emerged over the past several decades. For the purposes of critical and balanced comparison, at least, this is probably a good thing.

Given all this, how should the field move forward? Despite the short-term benefits of not having a dominant paradigm, it is probably in the field's longer-term interests to produce one, or at least generate more empirical consensus among scholars. At present, enough basic issues are still up in the air-including living standards in early modern China, ${ }^{27}$ the scale and significance of proto-industrialization in both China and large parts of Western Europe, ${ }^{28}$ and the detailed content of property and

23 For example, Robert Allen, The Brttish industrial Revolution in Global Perspective (2009); Daron Acemoglu \& James A. Robinson, Why Natrons fall: The Origins of Power, Prospertty and Poverty (2010); Patrick O'Brien, State Formation and the Construction of Institutions for the First Industrial Nation, in Instrtutional Change and Economic Development (Ha Joon Chang ed., 2007).

24 The argument for doing so is made most explicitly in R. BIN WONG AND JEAN-LAURENT ROSENTHAL, BEFORE and Beyond Divergence: The Politics of Economic Change in China and Europe (2011).

25 Douglass C. North \& Robert Paul Thomas, The Rise of the Western World: A New Economic History (1976); Douglass C. North, Instrtutions, Instrtuttonal Change and Economic Performance (1990); Daron Acemoglu, Simon Johnson \& James A. Robinson, Economic History and Political Science, 12(3) The Political Economst 4 (2005).

26 See, e.g., Peter C. Perdue, Property Rights on Imperial China's Frontiers, in LAND, ProperTy, AND THE ENvironment (John Richards, ed., 2001); Madeleine Zelin, A Critique of Rights of Property in Prewar China, in Contract and Property in Early Modern China 17 (Madeleine Zelin, Jonathan K. Ocko \& Robert Gardella eds., 2004).

27 See, e.g., the debate between Pomeranz, supra note 22; and Philip C.C. Huang, Development or Involution in Eighteenth-Century Britain and China?, 61 J. AsIAN STUD. 501 (2002).

28 See summary at Sheilagh C. Oginve, State Corporatism and Proto-Industry: The Württemberg BLACK FOREST, 1580-1797, at 16-34 (1997). 
contract regulations, ${ }^{29}$ - that the more abstract debates about framing, economic theory, and actual causation often have an apples-to-oranges quality. This does not imply, of course, that the field should seek out paradigms for the sake of having them-there are, as noted above, serious methodological risks to doing so-but it does mean that there is much room for development. A finer balance between empirical consensus and critical reexamination is probably something worth pursuing over the long run.

In addition, relatively few studies tackle both the issue of "which institutional differences contributed to the divergence" and the underlying issue of "how did those differences emerge in the first place." Most focus on the former-it is, after all, the defining question of the field-but not the second, sometimes due to lack of space, sometimes due to perceived methodological limitations. ${ }^{30}$ While certainly understandable at the individual level, a systemic failure to probe more deeply into the sociopolitical, and perhaps cultural, origins of institutions is a serious problem: institutions are, as any legal historian or social scientist will attest, inherently human constructs that undergo constant social scrutiny, and are often susceptible to change. It is therefore imperative to carefully consider why-and how-institutions exist in the first place, before employing them as analytical starting points in a study of economic divergence. One would otherwise find it difficult, if not impossible, to understand how these institutions functioned in real socioeconomic contexts, and, in turn, to accurately analyze their broader economic significance.

Some might argue that the analytical methods of institutional economics - by any measure the primary disciplinary driving force behind law-oriented "divergence studies" - are poorly equipped to study the underlying sociopolitical origins of institutional differences, ${ }^{31}$ but this is no reason to simply drop the inquiry. If econometric methods are difficult to execute, then the proper academic response should be to consider alternative methods, such as qualitative analysis, rather than to give up altogether. Whatever their other problems, the "illustrative comparisons" discussed above do at least display a wide range of methodologies and considerable intellectual flexibility, engaging scholars across multiple disciplines. There really is no reason why "divergence studies" cannot do the same. Moreover, given the high degree of synchronization between institutional economics and political economy, including several recent attempts to introduce "culture" into institutional economic models, one has to wonder whether the perceived methodological difficulties are actually that serious.

29 See, e.g., the differences between Philm C.C. Huang, Code, Custom, and Legal Practice nu China: The Qing and the Republic Compared (2001); Thomas Buoye, Manslaughter, Markets and Moral Economy: Violent Disputes over Property Rights in Eighteenth Century China (2000); and Taisu Zhang, Kinship, Property, and Agricultural Capitalism n Pre-Industrial China and England (Ph.D. Dissertation, Yale University History Department, 2014).

30 For discussion on the methodological incompatibilities between traditional institutional economics and "legal sociology," see Robert C. Ellickson, Law and Economics Discovers Social Norms, 27 J. LeGAL STUD. 537,542 (1998),

31 Id.

32 For example, Claudia R. Williamson \& Carrie B. Kerekes, Securing Private Property: Formal versus Informal Institutions, 54 J. Law \& ECoN. 537 (2011); Avner Greif, Cultural Beliefs and the Organization of Society: A Historical and Theoretical Reflection of Collectivist and Individualist Societies, 102 J. PoL. ECON. 912 (1994). 
"Divergence studies" also suffer from some of the same thematic limitations as the "legal encounters" literature discussed in section B: they, too, are innately limited by their subject matter, and are therefore predominantly concerned with institutional comparisons that have some plausible link to early modern economic divergence. This tends to privilege economic institutions or constitutional features over, say, criminal procedure or evidence rules, and rules out comparisons of medieval or classical institutions altogether. In general, the "illustrative comparisons" discussed in section A cover a much larger set of potential comparisons than either "divergence studies" or "legal encounters studies"-and therein lie both their intellectual appeal and some of their fundamental methodological difficulties. It is possible to see "category two" and "category three" comparisons simply as subsets of "category one" comparisons. And this justifies the Sino-European comparison by linking it to some cross-regional event with actual historical significance, for instance, actual institutional interaction between Chinese and European parties in category two and the "Great Divergence" in category three. One should not presume that this is an exhaustive list: surely there are other major historical events that would justify additional comparative categories. ${ }^{33}$

\section{CONCLUSION}

Is it really necessary, in the end, to justify the choice of comparing China and Europe? Is it not possible to believe that virtually any comparative exercise is worthwhile? The value of comparative exercises could lie, after all, in their ability to draw our attention to institutional features that we otherwise would have overlooked, rather than their ability to explain or illustrate inter-societal historical change. The choice of China and Europe is therefore a personal one, dependent only on the individual scholar's interests and abilities, and not fundamentally different, in an analytical sense, from any other comparison set.

This may be true as a general intellectual principle, but the specific binary of China-Europe comes with enough intellectual baggage - in the form of a long history of perceived "Eurocentricism" and "orientalism" - that an unconsidered, "knee-jerk" decision to compare those two regions tends to arouse certain kinds of suspicions. Given the still highly prevalent analytical imbalances and biases discussed in section A, those suspicions are not necessarily without merit. This is not a unique problem: in all likelihood, many comparisons between Asian, African, Middle Eastern, or Latin American regions with "the West" suffer from the same imbalances and biases. ${ }^{34}$ The problem, in the end, is that scholars still all too often fall back on the European experience as their "default reference point." None of this is to say that comparing other parts of the world to Europe is undesirable. On the contrary, given the arguably central importance of Europe in modern human history, such comparisons are very much indispensable. In other words, such comparisons should be performed with care, and preferably with some sense of methodological self-awareness. 
If we buy into the notion that any comparison, if properly executed, is intellectually worthwhile, then it is only fair to ask why there haven't more attempts to push the comparative exercise beyond the usual two-region model, into something resembling a "global legal history." Global history has rapidly gained significance in a number of fields, particularly economic, intellectual, and geopolitical history, ${ }^{35}$ and there does not seem to be an obvious reason why legal history should not at least consider joining the fray. If the point of comparative history is to highlight potentially overlooked issues and problems, then surely the larger the comparative set the better. Moreover, global comparisons potentially allow scholars to study socioeconomic and political behavior in a more general, and perhaps more abstract, fashion-in other words, to truly "theorize" about history.

This may sound fundamentally misguided to some. After all, the dominant historiographical trend of the past several decades has arguably been the celebration of contingency and complexity, not to mention systemic skepticism toward abstract theorizing. Without commenting on the general value of such skepticism, its applicability to comparative history is dubious, to say the least. The very point of comparison is to narrow down, to simplify the range of illustrative and causal possibility. ${ }^{36}$ There is little doubt that this should be done on the basis of contextualized and nuanced analysis of domestic histories, and with a healthy appreciation of the role of contingency. However, to argue against abstract analysis in comparative history is to take away the central objective of comparison.

Either we do not compare at all, or we must accept that comparative exercises aim, in the end, to theorize. Even when we focus on explaining differences between legal systems, we are attempting to highlight, via comparison, certain socioeconomic or political features that have a stronger claim to being "but-for" causes for those legal differences-which is fundamentally an act of abstraction and theorizing. If so, then perhaps the eventual production of a "global legal history" is something worth pursuing after all. 